\title{
Акцепторное легирование мышьяком при осаждении слоев CdTe из диметилкадмия и диизопропилтеллура
}

\author{
(C) В.С. Евстигнеев ${ }^{1}$, А.В. Чилясов ${ }^{1}$, А.Н. Моисеев $^{1}$, С.В. Морозов ${ }^{2}$, Д.И. Курицын ${ }^{2}$ \\ ${ }^{1}$ Институт химии высокочистых веществ им. Г.Г. Девятых Российской академии наук, \\ 603951 Нижний Новгород, Россия \\ ${ }^{2}$ Институт ффизики микроструктур Российской академии наук, \\ 603950 Нижний Новгород, Россия \\ E-mail: evstigvs@gmail.com
}

Поступила в Редакцию 31 августа 2020 г.

В окончательной редакции 9 сентября 2020 г.

Принята к публикации 9 сентября 2020 г.

Исследованы вхождение и активация мышьяка из трис-диметиламиноарсина в слои СdTе, выращенные методом химического осаждения из паров диметилкадмия и диизопропилтеллура на подложках GaAs. Вхождение мышьяка в СdTе зависит от кристаллографической ориентации слоев и увеличивается в ряду $(111) \mathrm{B} \rightarrow(100) \rightarrow(310)$. Концентрация мышьяка в слоях CdTe пропорциональна потоку трис-диметиламиноарсина в степени 1.4 и увеличивается при уменьшении соотношения диизопропилтеллур/диметилкадмий c 1.4 до 0.5. После осаждения слои CdTe:As имели p-тип проводимости с концентрацией мышьяка и дырок $10^{17}-7 \cdot 10^{18}$ и $2.7 \cdot 10^{14}-4.6 \cdot 10^{15} \mathrm{~cm}^{-3}$ соответственно, доля электрически активного мышьяка не превышала $\sim 0.3 \%$. После отжига в аргоне $\left(250-450^{\circ} \mathrm{C}\right)$ максимальная концентрация дырок и доля электрически активного мышьяка составили $1 \cdot 10^{17} \mathrm{~cm}^{-3}$ и $\sim 4.5 \%$ соответственно. Энергия ионизации мышьяка, определенная из температурной зависимости концентрации дырок, лежит в интервале $98-124$ мэВ. В спектрах низкотемпературной фотолюминесценции слоев проявляется пик с энергией $~ 1.51$ эВ, который отнесен к донорно-акцепторной рекомбинации, где акцептором является $\mathrm{As}_{\mathrm{Te}}$ с энергией ионизации $\sim 90$ мэВ.

Ключевые слова: теллурид кадмия, химическое осаждение из газовой фазы металлоорганических соединений, вторично-ионная масс-спектрометрия, активация мышьяка, отжиг.

DOI: 10.21883/FTP.2021.01.50377.9514

\section{1. Введение}

Теллурид кадмия (CdTe) - прямозонный полупроводник с шириной запрещенной зоны 1.48 эВ при $300 \mathrm{~K}$, близкой к идеальной для преобразования энергии солнечного спектра. CdTе имеет высокий коэффициент поглощения оптического излучения $\left(\sim 10^{5} \mathrm{~cm}^{-1}\right.$ при 700 нм), что позволяет поглощать $\sim 90 \%$ падающего излучения в слоях толщиной 2-3 мкм. Это делает CdTe одним из наиболее перспективных материалов для создания эффективных преобразователей солнечной энергии. Тонкопленочные солнечные элементы на основе поликристаллических структур $p$-CdTe $/ n-\mathrm{CdS}$ характеризуются одним из самых больших коэффициентов полезного действия $(22.1 \%$ [1]) среди солнечных элементов этого типа. Основной проблемой, ограничивающей их эффективность, является низкое напряжение холостого хода, величина которого зависит от концентрации дырок и времени жизни неосновных носителей заряда $p$-CdTe [2].

Достижение концентрации дырок $p>10^{17} \mathrm{~cm}^{-3}$ в слоях $p$-CdTe является одним из необходимых условий для изготовления эффективных солнечных элементов. Акцепторными свойствами в СdTе обладают некоторые собственные дефекты (например, $V_{\mathrm{Cd}}$ ), а также примеси элементов I $(\mathrm{Cu}, \mathrm{Ag}, \mathrm{Au})$ и $\mathrm{V}(\mathrm{N}, \mathrm{P}, \mathrm{As}, \mathrm{Sb})$ групп Периодической системы. Элементы V группы имеют малые энергии ионизации (энергии ионизации $\mathrm{N}, \mathrm{P}, \mathrm{As}$ составляют 56, 68 и 60-120 мэВ соответственно [3-6], $\mathrm{Sb}-280$ мэВ [7]) и заметно меньшие значения коэффициента диффузии по сравнению с элементами I группы, что делает их наиболее перспективными для управления электрофизическими свойствами CdTe. При этом энергии встраивания атомов $\mathrm{N}$ и $\mathrm{P}$ в кристаллическую решетку CdTe достаточно высоки и легирование ими в большинстве технологий осаждения представляет определенные трудности. Поэтому наиболее активно в настоящее время исследуется поведение в CdTe примеси As. Однако получение CdTe:As p-типа проводимости с высокой концентрацией дырок остается трудной научной задачей для различных методов роста. Это обусловлено амфотерным поведением мышьяка в CdTe (встраиваясь в анионную, $\mathrm{As}_{\mathrm{Te}}$, или катионную, $\mathrm{As}_{\mathrm{Cd}}$, подрешетки, мышьяк проявляет акцепторные или донорные свойства соответственно) и высокой степенью компенсации в материале, обусловленной образованием комплексов типа собственный дефект-примесь и АХ-центров $[8,9]$. В случае использования поликристаллического материала появляются эффекты, связанные с неоднородным распределением примеси в кристаллитах и на границах зерен. Исследование поведения примеси мышьяка в монокристаллических слоях $\mathrm{CdTe}$ упрощает задачу.

Получение эпитаксиальных слоев CdTe методом химического осаждения из паровой фазы металлоорганических соединений (MOCVD) дает возможность управ- 
лять концентрацией собственных дефектов и изменять условия вхождения примеси в слои за счет использования разнообразных прекурсоров и их соотношений. В качестве источников примеси мышьяка в методе MOCVD применяют арсин и его производные [10-12], a в последнее время наибольшее применение находит трис-диметила-миноарсин (ТДМАA, TDMAAs, $\left.\mathrm{As}\left[\mathrm{N}\left(\mathrm{CH}_{3}\right)_{2}\right]_{3}\right)$ [6,13-16]. Это связано с его невысокой температурой распада $\left(50 \%\right.$ при $\left.350^{\circ} \mathrm{C}[17]\right)$, а также низким давлением пара, что обеспечивает лучший контроль уровня легирования.

Цель данной работы - изучение закономерностей вхождения в условиях процесса MOCVD и активации мышьяка в эпитаксиальных слоях CdTe в зависимости от концентрации легирующего прекурсора (ТДМАА), кристаллографической ориентации подложки и соотношения исходных диметилкадмия (ДМК, DMCd) и диизопропилтеллура (ДИПТ, DIPTe), а также послеростового отжига слоев.

\section{2. Экспериментальная часть}

Эпитаксиальные слои CdTe выращивали из паров ДМК и ДИПТ в вертикальном кварцевом реакторе с нагретыми стенками $\left(\sim 300^{\circ} \mathrm{C}\right)$ при общем давлении 20 кПа и температуре пьедестала $330^{\circ} \mathrm{C}$. В качестве подложек использовали „еріready“ пластины полуизолирующего GaAs с кристаллографической ориентацией $(100)$, отклонение $4^{\circ} \rightarrow\langle 110\rangle,(310) \pm 0.5^{\circ}$ и (111)B $\pm 0.5^{\circ}$. Чистота исходных металлоорганических соединений (МОС) составляла не менее 99.999\% (производитель ООО „ЭЛМОС“6). В качестве газа-носителя использовали водород, очищенный диффузией через Pd-фильтр.

Перед осаждением слоев подложки отжигали при $550^{\circ} \mathrm{C}$ в течение 15 мин в потоке водорода. Предварительно на подложки наносили буферный слой нелегированного CdTe толщиной 2-3 мкм для предотвращения диффузии компонентов подложки в слой. Величина потока ДМК была фиксированной и составляла $1 \cdot 10^{-4}$ моль/мин. Величину потока ДИПТ изменяли от $5 \cdot 10^{-5}$ до $1.4 \cdot 10^{-4}$ моль/мин (соотношение потоков ДИПТ/ДМК $=0.5-1.4)$, а потока ТДМАА - от $2 \cdot 10^{-7}$ до $1 \cdot 10^{-6}$ моль/мин. Общий поток водорода в реактор составлял 3 норм.л/мин. В аналогичных условиях также выращивали нелегированные слои CdTe (без добавления ТДМАА в газовую фазу) и использовали их в качестве образцов сравнения для надежной интерпретации свойств легированных слоев. Кристаллографическая ориентация всех выращенных слоев совпадала с ориентацией используемых подложек по данным метода двухкристальной рентгеновской дифрактометрии.

Толщину выращенных слоев определяли из инфракрасных (ИК) спектров пропускания, полученных на фурье-спектрометре Nicolet 6700. Спектры были сняты при $295 \mathrm{~K}$ в диапазоне волновых чисел $500-6000 \mathrm{~cm}^{-1}$ с разрешением $0.5 \mathrm{~cm}^{-1}$. Концентрацию мышьяка и ее распределение по толщине структур определяли методом вторично-ионной масс-спектрометрии (ВИМС) на приборе TOF.SIMS-5. Концентрационные профили были получены путем чередования импульсных ионных пучков: анализирующего $\mathrm{Bi}_{3}^{+}$с энергией 25 кэВ, ток 1 пА, и распыляющего $\mathrm{Cs}^{+}$c энергией 1 кэВ. Абсолютная величина концентрации мышьяка была рассчитана путем количественного анализа ВИМС-спектров с применением эталонных образцов, полученных методом ионной имплантации.

Темновые электрофизические параметры выращенных пленок определяли из измерений эффекта Холла в постоянном магнитном поле $B=0.5$ Тл на образцах с размерами $1.5 \times 1.5 \mathrm{~cm}$ и при толщине легированного слоя не менее 3 мкм в диапазоне температур 240-340 K. Омические контакты диаметром $\sim 1.5$ мм к $p$-CdTe изготавливали путем химического осаждения золота по углам образцов из водного раствора $\mathrm{HAuCl}_{4} \cdot 4 \mathrm{H}_{2} \mathrm{O}$.

Изучение природы нахождения атомов мышьяка в кристаллической решетке $\mathrm{CdTe}$, влияния условий получения и послеростовых отжигов слоев на поведение примеси проводили методом стационарной фотолюминесценции (ФЛ). Для регистрации ФЛ использовали решеточный спектрометр Acton SP2500i с базой 0.5 м, оснащенный CCD-камерой Spec-10 : 256E (Princeton Research) с разрешением 0.5 нм. Возбуждение ФЛ осуществляли при помощи фемтосекундного Тi : Sapphire-лазера Tsunami (Spectra-Physics), с удвоением по частоте до длины волны 390 нм. Средняя мощность возбуждения составляла 10 мВт при диаметре пятна засветки $\sim 100$ мкм. Измерения проводились при температуре $4 \mathrm{~K}$, для поддержания температуры образец помещался в криостат замкнутого цикла.

Для увеличения концентрации электрически активного мышьяка проводили послеростовые отжиги слоев $\mathrm{CdTe}$ в горизонтальной кварцевой трубе в потоке высокочистого аргона (0.3 норм.л/мин) в диапазоне температур $250-450^{\circ} \mathrm{C}$ с последующим резким охлаждением $\left(30-50^{\circ} \mathrm{C} / \mathrm{мин}\right)$.

\section{3. Результаты и их обсуждение}

На рис. 1 представлено концентрационное распределение мышьяка по толщине слоев CdTe кристаллографических ориентаций (100), (310) и (111)В, выращенных в одном процессе при соотношении потоков ДИПТ/ДМК $=1$ и ступенчатом увеличении потока ТДМАА от $2 \cdot 10^{-7}$ до $1 \cdot 10^{-6}$ моль/мин. Повышение потока ТДМАА приводит к увеличению содержания мышьяка в слоях CdTe всех кристаллографических ориентаций. При изменении потока ТДМАА для слоев CdTe (100) и (310) наблюдается резкий профиль изменения концентрации мышьяка, в то время как для $\mathrm{CdTe}(111) \mathrm{B}$ наблюдается плавное изменение его содержания. Это объясняется большей шероховатостью 
поверхности $\mathrm{CdTe}(111) \mathrm{B}$ в наших условиях осаждения, что приводит к усреднению результатов измерения концентрации мышьяка по глубине и отсутствию резких границ между областями с разным уровнем легирования.

Зависимость содержания мышьяка в слоях $\mathrm{CdTe}(100)$ и (310) от потока ТДМАА (рис. 1) описывается выражением

$$
C_{\mathrm{As}} \propto[\mathrm{TDMAAs}]^{a},
$$

где $a \approx-1.4$.

Показатель степенной зависимости концентрации мышьяка в CdTe от потока ТДМАА имеет дробное значение. Из-за сложности химической системы выделить конкретную лимитирующую стадию процесса вхождения As в CdTe представляется сложной задачей. Из [17] известно, что лимитирующей стадией газофазного термического разложения ТДМАА в водороде является гомолитический разрыв связи As-N. Образующиеся в процессе распада радикалы диметиламинила и водорода взаимодействуют с исходной молекулой ТДМАА, что увеличивает скорость ее разложения. В процессе роста CdTe реакции с участием прекурсоров могут проходить как в газовой фазе, так и на поверхности. Отклонение $a$ от 1 может быть обусловлено вхождением мышьяка в слои не только в результате сложной кинетики распада ТДМАА, но и поступлением мышьяка по другим каналам совместного распада ТДМАА, ДМК и ДИПТ, осложненным влиянием поверхности осаждения. В данном случае мы можем исключить образование аддукта между ДМК, ТДМАА и продуктами его распада [14], поскольку повышение потока ТДМАА от $2 \cdot 10^{-7}$ до $1 \cdot 10^{-6}$ моль/мин не приводило к увеличению скорости осаждения $\mathrm{CdTe}$ на изучаемых ориентациях роста. Для легированных из ТДМАА слоев CdTe (100), выращенных из паров диэтилтеллура (ДЭТ) и ДМК, ранее нами получена аналогичная степенная зависимость с близким по значению коэффициентом $a=1.5$ [13].

Результаты эксперимента по выращиванию слоев $\mathrm{CdTe}(100)$, (310) и (111)В в одном процессе при изменяющемся соотношении ДИПТ/ДМК и фиксированном потоке ТДМАА $5 \cdot 10^{-7}$ моль/мин представлены на рис. 2. Для всех кристаллографических ориентаций различимы три ступеньки легирования. Как и ожидалось $[6,13]$, вхождение мышьяка в слои CdTe увеличивается при уменьшении соотношения ДИПТ/ДМК от 1.4 до 0.5. Изменение соотношения ДИПТ/ДМК в газовой фазе позволяет управлять эффективным соотношением $\mathrm{Te} / \mathrm{Cd}$ на ростовой поверхности и переходить по условиям осаждения от обогащения Те к обогащению $\mathrm{Cd}$. В условиях обогащения $\mathrm{Cd}$ понижается энергия образования вакансий теллура $V_{\text {Te}}$, что увеличивает включение мышьяка в анионную подрешетку [14].

Из рис. 1 и 2 следует, что вхождение мышьяка в CdTe имеет выраженную зависимость от кристаллографической ориентации роста и увеличивается в ряду $(111) \mathrm{B} \rightarrow(100) \rightarrow(310)$. Это свидетельствует о лимитирующей роли поверхностных стадий в процессе

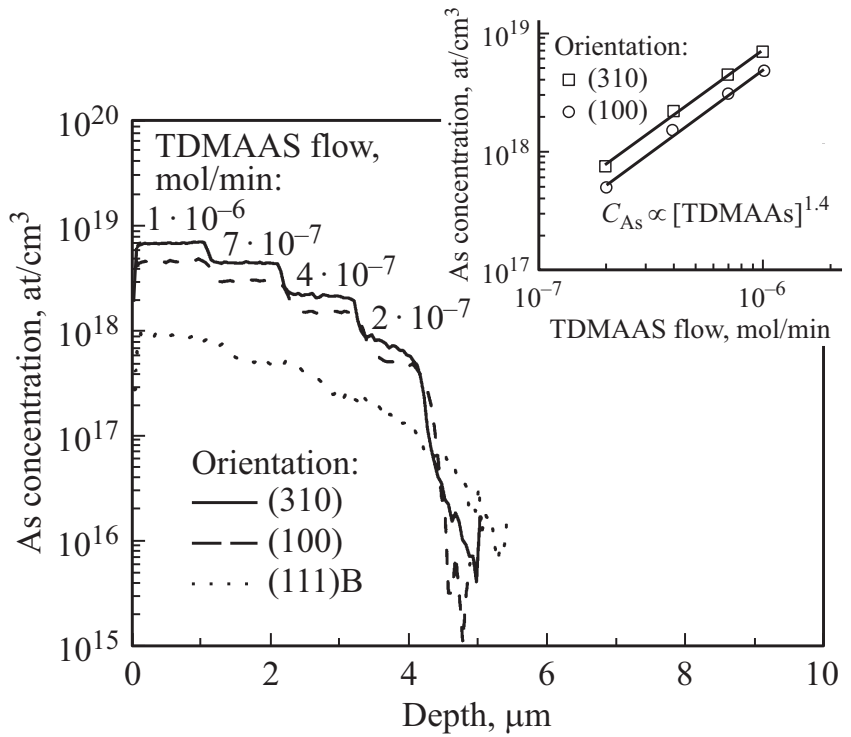

Рис. 1. Концентрационное распределение As по толщине слоев CdTe:As (100), (310) и (111)В, выращенных в одном процессе при изменяющемся потоке ТДМАА. Соотношение ДИПТ/ДМК $=1$. На вставке - зависимость концентрации As в слоях CdTe:As (100) и (310) от потока ТДМАА.

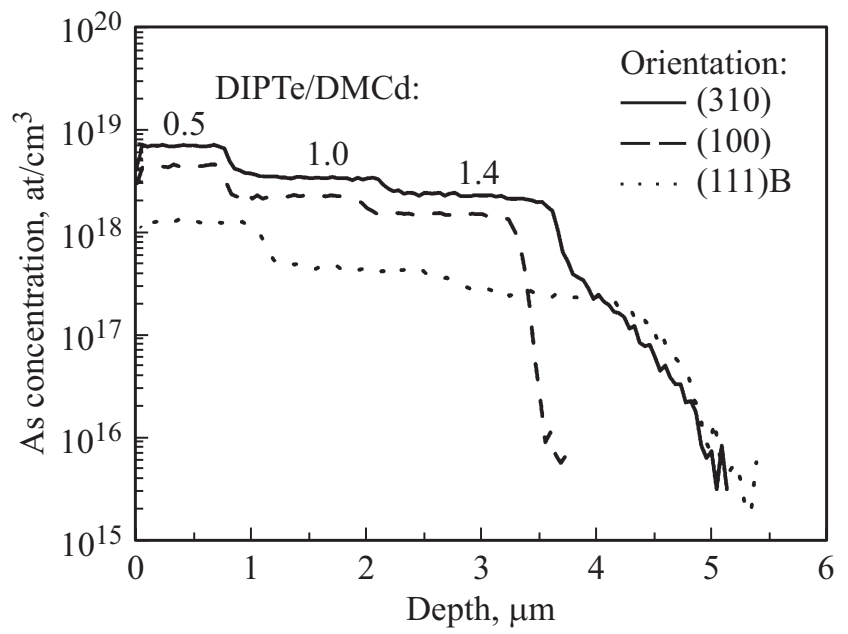

Рис. 2. Концентрационное распределение As по толщине слоев CdTe:As (100), (310) и (111)В, выращенных в одном процессе при изменяющемся соотношении ДИПТ/ДМК. Поток ТДМАА $-5 \cdot 10^{-7}$ моль/мин.

легирования. Наименьшее вхождение мышьяка наблюдается для Те-обогащенной поверхности (111)В, которая содержит атомы с одной оборванной связью, доступной для присоединения атома $\mathrm{Cd}$. Содержание мышьяка для ориентации (100) выше, чем для (111)В, поскольку атомы $\mathrm{Cd}$ или Те на ее поверхности содержат по две оборванные связи [10]. Нереконструированная поверхность (310) кристаллов типа алмаза и сфалерита представляет собой систему террас (100) равной ширины, разделенных ступенями, распространяющимися вдоль 


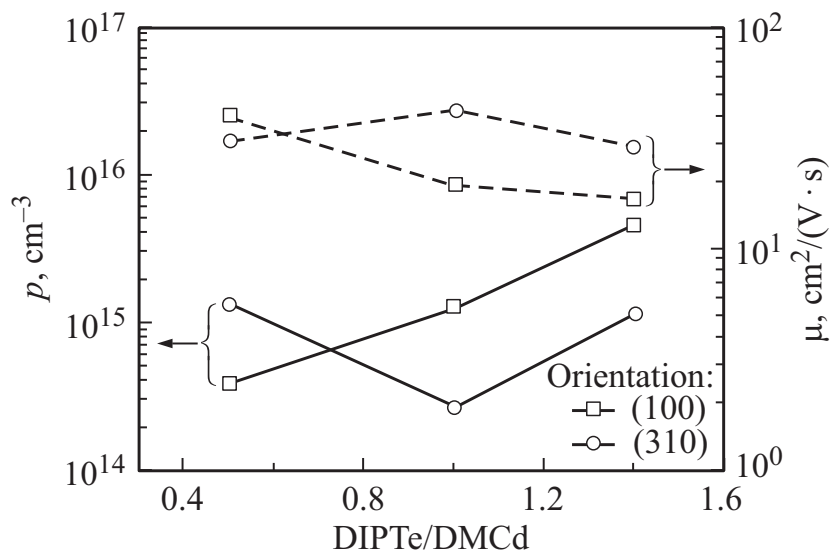

Рис. 3. Зависимость концентрации $(p)$ и подвижности $(\mu)$ дырок $(T=295 \mathrm{~K}, B=0.5$ Тл) в слоях CdTe : As (100) и (310) от отношения потоков ДИПТ/ДМК.

направлений [100] [18]. Поэтому вероятность вхождения мышьяка на ней должна быть выше, чем для ориентации (100).

Для изучения электрофизических свойств использовали легированные образцы CdTe (100) и (310), выращенные при соотношениях ДИПТ/ДМК $=0.5,1,1.4$ и потоке ТДМАА $5 \cdot 10^{-7}$ моль/мин. В соответствии с результатами анализа методом ВИМС концентрация мышьяка в полученных слоях лежала в диапазоне $(1-7) \cdot 10^{18} \mathrm{~cm}^{-3}$, в пределах погрешности измерений совпадая с данными для образцов со ступенчатым профилем легирования (рис. 2). В качестве образцов сравнения использовали нелегированные слои CdTe, полученные в тех же условиях без потока ТДМАА. Все нелегированные образцы были высокоомными, их удельное сопротивление превышало $10^{6}$ Ом · см, а удельное сопротивление легированных слоев лежало в диапазоне $(0.8-5) \cdot 10^{2}$ Ом · см. Зависимости концентрации и подвижности дырок в этих слоях от соотношения ДИПТ/ДМК представлены на рис. 3. Для легированных слоев $\mathrm{CdTe}$ (100) концентрация дырок растет от $3.8 \cdot 10^{14}$ до $4.6 \cdot 10^{15} \mathrm{~cm}^{-3}$, а их подвижность уменьшается от 40 до $17 \mathrm{~cm}^{2} /(\mathrm{B} \cdot \mathrm{c})$ при увеличении соотношения ДИПТ/ДМК от 0.5 до 1.4. В то же время для слоев $\mathrm{CdTe}$ (310) при ДИПТ/ДМК = 1 наблюдаются минимум концентрации и максимум подвижности дырок на уровне $2.7 \cdot 10^{14} \mathrm{~cm}^{-3}$ и $42 \mathrm{~cm}^{2} /(\mathrm{B} \cdot \mathrm{c})$ соответственно. Таким образом, доля электрически активного мышьяка в полученных слоях несколько увеличивалась с увеличением отношения ДИПТ/ДМК, но не превышала $0.3 \%$.

Электрофизические параметры слоев CdTe:As (100) и их зависимость от отношения ДИПТ/ДМК хорошо согласуются с результатами работы [16], в которой проводили легирование $\mathrm{CdTe}(100)$ мышьяком с использованием тех же исходных соединений при более высокой температуре $400^{\circ} \mathrm{C}$. Полученные слои имели $p$-тип проводимости с концентрацией дырок в диапазоне $8 \cdot 10^{14}-3 \cdot 10^{15} \mathrm{~cm}^{-3}$, которая росла с увеличением отношения ДИПТ/ДМК. Такая зависимость объяснялась уменьшением степени самокомпенсации мышьяка за счет понижения его общей концентрации в слоях CdTe при росте в избытке ДИПТ. В модели компенсации As в CdTe, предложенной в работе [19], рассматривается несколько типов компенсирующих дефектов: $\mathrm{As}_{\mathrm{Cd}}$ и AX-центры, проявляющие донорные свойства, а также наиболее вероятные комплексы $V_{\mathrm{Cd}}-\mathrm{As}_{\mathrm{Cd}}$, которые дают глубокий акцепторный уровень ( 293 мэВ $),$ и $V_{\mathrm{Cd}}-\mathrm{As}$ Те создающие глубокий донорный уровень ( 377 мэВ). Увеличение избытка ДИПТ в нашем случае может приводить к увеличению концентрации вакансий кадмия $V_{\mathrm{Cd}}$ и их комплексов с мышьяком $V_{\mathrm{Cd}}-\mathrm{As}_{\mathrm{Cd}}$, с одновременным уменьшением содержания компенсирующих доноров $V_{\mathrm{Cd}}-\mathrm{As}_{\mathrm{Te}}$. Косвенно на увеличение концентрации ионизованных дефектов указывает заметное уменьшение подвижности носителей заряда в слоях, полученных в избытке ДИПТ.

В случае слоев CdTe: As (310) зависимость имеет более сложный характер, что может быть обусловлено отличной от CdTe : As (100) в этих условиях осаждения равновесной концентрацией компенсирующих мышьяк собственных дефектов и их комплексов.

Для увеличения доли электрически активного мышьяка проводили серии отжигов легированных слоев $\mathrm{CdTe}(100)$ в потоке аргона. При этом происходило изменение равновесных концентраций собственных дефектов, комплексов мышьяк-дефект и АХ-центров. Отжигу были подвергнуты также нелегированные слои $\mathrm{CdTe}(100)$, удельное сопротивление которых после обработки превышало $10^{6} \mathrm{OM} \cdot \mathrm{cm}$. На рис. 4 представлены зависимости концентрации и подвижности дырок в слоях CdTe:As (100), выращенных при отношениях ДИПТ/ДМК $=0.5,1,1.4$, от температуры отжига в течение 15 мин. Из рисунка видно, что изменение концентрации дырок в слоях CdTe:As (100), выращенных при разных соотношениях ДИПТ/ДМК,

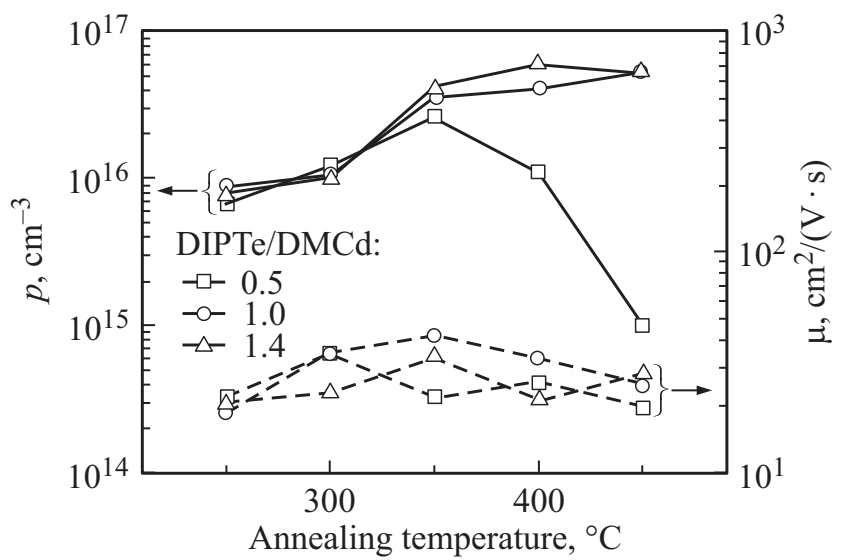

Рис. 4. Зависимость концентрации ( $p)$ и подвижности $(\mu)$ дырок $(T=295 \mathrm{~K}, B=0.5$ Тл) в слоях CdTe:As (100), выращенных при различном соотношении ДИПТ/ДМК, от температуры отжига. Время отжига 15 мин. 
обнаруживает схожее поведение после отжигов при температурах до $350^{\circ} \mathrm{C}$. После отжига при температуре $T_{\text {ann }}=250^{\circ} \mathrm{C}$ концентрация дырок в слоях повышается до $p=(7-10) \cdot 10^{15} \cdot \mathrm{cm}^{-3}$. Для слоев, выращенных при ДИПТ/ДМК $=1$ и 1.4, концентрация дырок растет далее с повышением температуры отжига и достигает максимума $p=(5-6) \cdot 10^{16} \mathrm{~cm}^{-3}$ при $T_{\mathrm{ann}}=400-450^{\circ} \mathrm{C}$. Заметно отличается изменение электрофизических параметров после отжига образцов, выращенных при ДИПТ/ДМК $=0.5$. При повышении температуры отжига от 250 до $350^{\circ} \mathrm{C}$ концентрация дырок в слоях растет, достигая значений $p=(2-2.5) \cdot 10^{16} \mathrm{~cm}^{-3}$, а затем резко падает с увеличением температуры отжига до уровня $p=1 \cdot 10^{15} \mathrm{~cm}^{-3}$. Подвижность дырок в слоях растет с повышением температуры отжига, проходит через максимум $33-42 \mathrm{~cm}^{2} /(\mathrm{B} \cdot \mathrm{c})$ при температурах $300-350^{\circ} \mathrm{C}$, а затем уменьшается. Наибольшее значение доли электрически активного мышьяка после таких отжигов в слоях $\mathrm{CdTe}(100)$ находится на уровне $\sim 4.5 \%$. Полученные нами значения концентрации дырок и доли электрически активного мышьяка близки к данным работ $[11,16]$, в которых из паров ДИПТ и ДМК были получены слои CdTe:As c концентрацией дырок до $p=6 \cdot 10^{16} \mathrm{~cm}^{-3}$. Доля электрически активного мышьяка при этом составляла $\sim 3 \%$ в работе [11] и не превышала $1 \%$ в работе [16].

Известно, что высокотемпературный отжиг приводит к изменению равновесной концентрации как собственных, так и связанных с примесными атомами дефектов в легированных слоях, а последующее быстрое охлаждение - к „закалке“ этого состояния. Повышение температуры отжига образцов CdTe, полученных при ДИПТ/ДМК $=1.0$ и 1.4, по-видимому, приводит к уменьшению концентрации обусловленных мышьяком $\mathrm{AX}$-центров $\left(\mathrm{As}_{\mathrm{Te}}^{+}\right)$, состояние которых в кристаллической решетке является метастабильным, в пользу основного акцепторного состояния $\mathrm{As}_{\mathrm{Te}}^{-}$. Это понижает степень компенсации акцепторов в слоях и увеличивает концентрацию дырок. Более сложное изменение электрофизических параметров при отжиге образцов $\mathrm{CdTe}: \mathrm{As}$, полученных при ДИПТ/ДМК $=0.5$, вероятно, объясняется наличием в слоях существенной концентрации межузельного кадмия $\mathrm{Cd}$, который самостоятельно образует глубокий донорный уровень с энергией ионизации 330 мэВ [20] и может взаимодействовать при более высоких температурах отжига с дефектами, связанными с мышьяком.

Концентрация дырок в слоях, выращенных при ДИПТ/ДМК $=0.5$ и 1.4, практически не зависит от времени отжига и колеблется в интервалах $p=(0.8-2) \cdot 10^{16}$ и $(5-6) \cdot 10^{16} \mathrm{~cm}^{-3}$ соответственно. Подобная зависимость уже наблюдалась нами ранее во время отжига слоев CdTe:As (100), выращенных с использованием диэтилтеллура (ДЭТ), более термически стойкого МОС теллура, при $355^{\circ} \mathrm{C}$ и отношении ДЭТ/ДМК $=0.5$, т.е. в избытке ДМК [6].

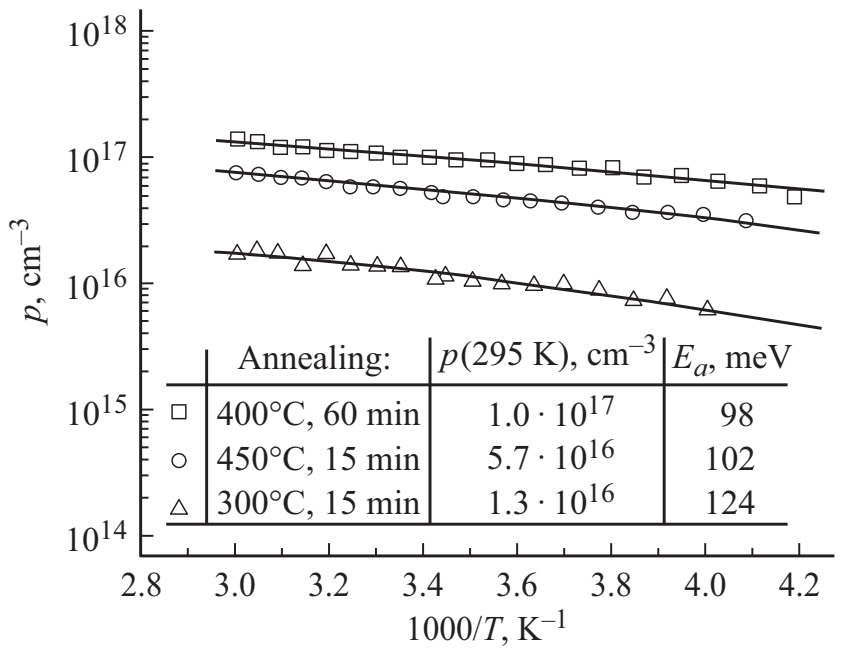

Рис. 5. Зависимость концентрации дырок от обратной температуры в слоях CdTe:As (100), отожженных в различных условиях. ДИПТ/ДМК $=1$.

Концентрация дырок в слоях, выращенных при отношении ДИПТ/ДМК $=1$, увеличивается с продолжительностью отжига и достигает максимального значения $p=1 \cdot 10^{17} \mathrm{~cm}^{-3}$ в течение 60 мин. Этот результат несколько выше значений, полученных в $[11,12,15,16]$, и близок к рекордным значениям концентраций дырок $p=(1-2) \cdot 10^{17} \mathrm{~cm}^{-3}$ в легированных мышьяком эпитаксиальных слоях $\mathrm{CdTe}$, полученных методом MOCVD $[6,13,21,22]$. Тем не менее доля электрически активного мышьяка в слоях CdTe, полученных с использованием ДИПТ $(\sim 4.5 \%)$, существенно ниже доли в слоях CdTe, полученных ранее с использованием ДЭТ (10-85\%) [6]. Это может быть обусловлено прежде всего уменьшением концентрации вакансий теллура $\left(V_{\mathrm{Te}}\right)$ в решетке CdTe из-за использования менее термически устойчивого МОС теллура и, следовательно, большей вероятности встраивания As в катионную подрешетку.

На рис. 5 представлены температурные зависимости концентрации дырок в слоях CdTe:As (100), выращенных при отношении ДИПТ/ДМК $=1$ и отожженных в различных режимах. Из данных зависимостей была определена энергия ионизации акцепторного уровня по модели, предполагающей наличие одного дискретного акцепторного уровня вблизи параболической валентной зоны и аналогичного донорного уровня вблизи зоны проводимости [23]. Значения энергии ионизации мышьяка в слоях CdTe:As, определенные из температурных зависимостей концентрации дырок, лежат в интервале 98-124 мэВ. Полученные данные согласуются со значениями энергии ионизация мышьяка в слоях $\mathrm{CdTe}$, представленными в литературе (60-120 мэВ $[5,6,12,16,21])$.

Энергия ионизации мышьяка была оценена из измерений низкотемпературной ФЛ. На рис. 6 приведены спектры низкотемпературной ФЛ слоев CdTe:As (100) с концентрацией дырок $1 \cdot 10^{16}, 4.1 \cdot 10^{16}$ и $5.2 \cdot 10^{16} \mathrm{~cm}^{-3}$, 


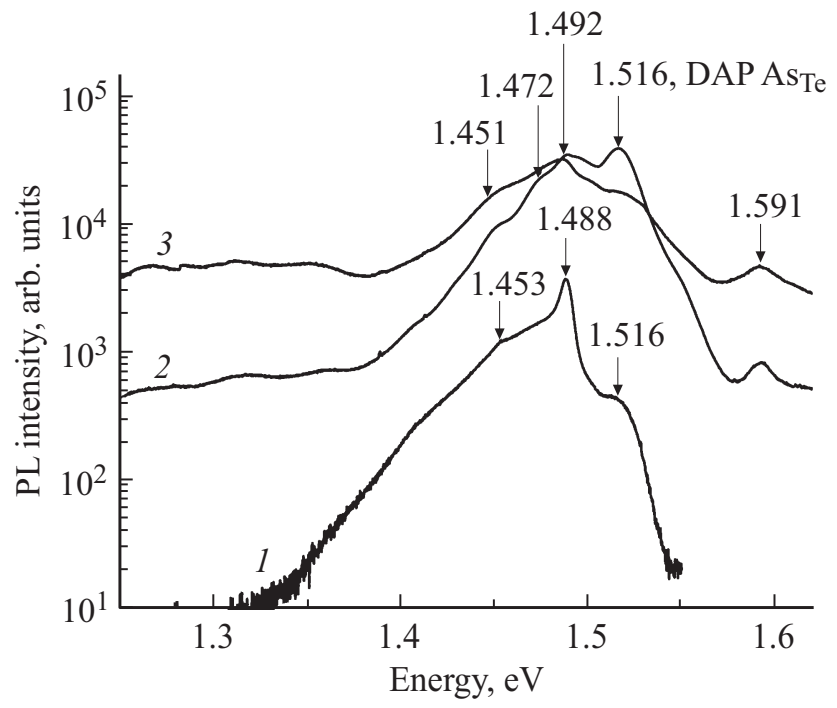

Рис. 6. Изменение спектров низкотемпературной ФЛ (4K) слоев CdTe:As (100) в зависимости от условий отжига. Соотношение ДИПТ/ДМК $=1$, концентрация мышьяка в слоях $2.2 \cdot 10^{18} \mathrm{~cm}^{-3}$, время отжига 15 мин. Температура отжига и концентрация дырок: $1-300^{\circ} \mathrm{C}, 1.1 \cdot 10^{16} \mathrm{~cm}^{-3} ; 2-400^{\circ} \mathrm{C}$, $4.1 \cdot 10^{16} \mathrm{~cm}^{-3} ; 3-450^{\circ} \mathrm{C}, 5.2 \cdot 10^{18} \mathrm{~cm}^{-3}$.

выращенных при соотношении ДИПТ/ДМК $=1$ и отожженных при 300,400 и $450^{\circ} \mathrm{C}$ соответственно. В спектре ФЛ слоя с концентрацией дырок $1 \cdot 10^{16} \mathrm{~cm}^{-3}$ линия с энергией 1.516 эВ ассоциируется с донорноакцепторной рекомбинацией и имеет фононные повторения в низкоэнергетической области спектра при 1.488 и 1.453 эВ [24]. По мере увеличения концентрации дырок до $5.2 \cdot 10^{16} \mathrm{~cm}^{-3}$ полоса при 1.516 эВ становится интенсивнее и приобретает более развитую фононную структуру. Пик с энергией 1.591 эВ в литературе связывают с рекомбинацией экситона, связанного на акцепторе $\mathrm{As}_{\mathrm{Te}}$ с энергией ионизации 90 мэВ [24]. Используя правило Хейнса [25], получим энергию ионизации для данного акцептора 92 мэВ.

\section{4. Заключение}

В вертикальном кварцевом реакторе методом MOCVD на подложках GaAs (100), (310), (111)В при $330^{\circ} \mathrm{C}$ и давлении 20 кПа выращены легированные мышьяком из ТДМАА эпитаксиальные слои СdTe. По данным ВИМС, содержание мышьяка находилось в интервале $2 \cdot 10^{17}-7 \cdot 10^{18} \mathrm{~cm}^{-3}$. Установлено, что зависимость содержания мышьяка в слоях $\mathrm{CdTe}(100)$ и (310) описывается уравнением $C_{\mathrm{As}} \propto[\text { ТДМАА }]^{1.4}$ в диапазоне потоков ТДМАА $2 \cdot 10^{-7}-1 \cdot 10^{-6}$ моль/мин. При уменьшении соотношения ДИПТ/ДМК от 1.4 до 0.5 концентрация мышьяка в $\mathrm{CdTe}$ увеличивается, что обусловлено изменением эффективного соотношения атомов $\mathrm{Te} / \mathrm{Cd}$ на ростовой поверхности. Вхождение мышьяка в $\mathrm{CdTe}$ зависит от кристаллографической ориентации роста и увеличивается в ряду $(111) \mathrm{B} \rightarrow(100) \rightarrow(310)$. Это свидетельствует о лимитирующей роли поверхностных стадий в процессе легирования. Показано, что после осаждения слои CdTe: As (100) и (310) имели p-тип проводимости с концентрацией дырок в диапазоне $2.7 \cdot 10^{14}-4.6 \cdot 10^{15} \mathrm{~cm}^{-3}$, зависящей от соотношения ДИПТ/ДМК. Проведение послеростовых отжигов слоев CdTe:As (100) в аргоне привело к частичной активации мышьяка как акцептора. Максимальная концентрация дырок и доля электрически активного мышьяка составили $1 \cdot 10^{17} \mathrm{~cm}^{-3}$ и $\sim 4.5 \%$ соответственно после отжига слоев CdTe:As (100) при $400^{\circ} \mathrm{C}$ в течение 60 мин. Из температурных зависимостей концентрации дырок в слоях CdTe: As (100) определена энергия ионизации мышьяка, значения которой лежат в интервале 98-124мэВ. На спектрах ФЛ при 4 К выявлен пик донорно-акцепторной рекомбинации с энергией $\sim 1.51$ эВ, где в качестве акцептора выступает мышьяк в анионной подрешетке $\mathrm{As}_{\mathrm{Te}}$ с энергией ионизации $\sim 90$ мэВ.

\section{Благодарности}

Анализ структур методом ВИМС выполнен на оборудовании ЦКП „Диагностика микро- и наноструктур“ Ярославского государственного университета.

\section{Финансирование работы}

Работа выполнена по государственному заданию Министерства науки и образования РФ (тема № 0095-2019-0004) и частично поддержана Российским научным фондом (проект № 17-12-01360).

\section{Конфликт интересов}

Авторы заявляют, что у них нет конфликта интересов.

\section{Список литературы}

[1] M.A. Green, E.D. Dunlop, D.H. Levi, J. Hohl-Ebinger, M. Yoshita, A.W.Y. Ho-Baillie. Progr. Photovolt.: Res. Appl., 27 (7), 565 (2019).

[2] Kanevce, M.O. Reese, T.M. Barnes, S.A. Jensen, W.K. Metzger. J. Appl. Phys., 121 (21), 214506 (2017).

[3] E. Molva, K. Saminadayar, J.L. Pautrat. Solid State Commun., 48 (11), 955 (1983).

[4] M. Soltani, M. Certier, R. Evrard, E. Kartheuser. J. Appl. Phys., 78 (9), 5626 (1995).

[5] J.M. Arias, S.H. Shin, D.E. Cooper, M. Zandian, J.G. Pasko, E.R. Gertner, R.E. DeWames, J. Singh. J. Vac. Sci. Technol. A, 8 (2), 1025 (1990).

[6] V.S. Evstigneev, A.V. Chilyasov, A.N. Moiseev, M.V. Kostunin. TSF, 689, 137514 (2019).

[7] Е.С. Никонюк, З.И. Захарук, В.Л. Шляховый, П.М. Фочук, А.И. Раренко. ФТП, 35 (4), 417 (2001).

[8] D.J. Chadi, C.H. Park. Mater. Sci. Forum, 196, 285 (1995).

[9] S.H. Wei, S.B. Zhang. Phys. Rev. B, 66 (15), 155211 (2002). 
[10] L. Svob, I. Cheze, A. Lusson, D. Ballutaud, J.F. Rommeluere, Y. Marfaing. J. Cryst. Growth, 184, 459 (1998).

[11] P.Y. Su, R. Dahal, G.C. Wang, S. Zhang, T.M. Lu, I.B. Bhat. J. Electron. Mater., 44 (9), 3118 (2015).

[12] M. Ekawa, K. Yasuda, T. Ferid, M. Saji. J. Appl. Phys., 71 (6), 2669 (1992).

[13] А.В. Чилясов, А.Н. Моисеев, В.С. Евстигнеев, Б.С. Степанов, М.Н. Дроздов. Неорг. матер., 52 (12), 1284 (2016). [A.V. Chilyasov, A.N. Moiseev, V.S. Evstigneev, B.S. Stepanov, M.N. Drozdov. Inorg. Mater., 52 (12), 1210 (2016).]

[14] В.С. Евстигнеев, А.В. Чилясов, А.Н. Моисеев, М.В. Костюнин. Неорг. матер., 55 (10), 1040 (2019). [V.S. Evstigneev, A.V. Chilyasov, A.N. Moiseev, M.V. Kostyunin. Inorg. Mater., 55 (10), 984 (2019).]

[15] G. Kartopu, O. Oklobia, D. Turkay, D.R. Diercks, B.P. Gorman, V. Barrioz, S. Campbell, J.D. Major, M.K. Al Turkestani, S. Yerci, T.M. Barnes, N.S. Beattie, G. Zoppi, S. Jones, S.J.C. Irvine. Sol. Energy Mater. Sol. Cells, 194, 259 (2019).

[16] P.Y. Su, C. Lee, G.C. Wang, T.M. Lu, I.B. Bhat. J. Electron. Mater., 43 (8), 2895 (2014).

[17] S. Salim, C.K. Lim, K.F. Jensen. Chem. Mater., 7 (3), 507 (1995).

[18] М.В. Якушев, Д.В. Брунев, Ю.Г. Сидоров. Поверхность. Рентгеновские, синхротронные и нейтронные исследования, № 1, 89 (2010).

[19] T. Ablekim, S.K. Swain, W.J. Yin, K. Zaunbrecher, J. Burst, T.M. Barnes, D. Kuciauskas, S.H. Wei, K.G. Lynn. Sci. Rep., 7 (1), 4563 (2017).

[20] B.E. McCandless, W.A. Buchanan, C.P. Thompson, G. Sriramagiri, R.J. Lovelett, J. Duenow, D. Albin, S. Jensen, E. Colegrove, J. Moseley, H. Moutinho, S. Harvey, M. AlJassim, W.K. Metzger. Sci. Rep., 8 (1), 1 (2018).

[21] S.K. Ghandhi, N.R. Taskar, I.B. Bhat. Appl. Phys. Lett., 50 (14), 900 (1987).

[22] L. Svob, Y. Marfaing, B. Clerjaud, D. Côte, A. Lebkiri, R. Druilhe. J. Cryst. Growth, 159 (1-4), 72 (1996).

[23] W. Scott, E.L. Stelzer, R.J. Hager. J. Appl. Phys., 47 (4), 1408 (1976).

[24] G.L. Burton, D.R. Diercks, O.S. Ogedengbe, P.A.R.D. Jayathilaka, M. Edirisooriya, T.H. Myers, K.N. Zaunbrecher, J. Moseley, T.M. Barnes, B.P. Gorman. Sol. Energy Mater. Sol. Cells, 182, 68 (2018).

[25] J.R. Haynes. Phys. Rev. Lett., 4 (7), 361 (1960).

Редактор Л.В. Шаронова

\section{Arsenic doping in the deposition of CdTe layers from dimethylcadmium and diisopropyltellurium}

\author{
V.S. Evstigneev ${ }^{1}$, A.V. Chilyasov ${ }^{1}$, A.N. Moiseev ${ }^{1}$, \\ S.V. Morozov' ${ }^{2}$, D.I. Kuritsyn ${ }^{2}$ \\ ${ }^{1}$ Devyatykh Institute of Chemistry \\ of High-Purity Substances, \\ Russian Academy of Sciences, \\ 603951 Nizhny Novgorod, Russia \\ 2 Institute for Physics of Microstructures, \\ Russian Academy of Sciences, \\ 603950 Nizhny Novgorod, Russia
}

Abstract The incorporation and activation of arsenic from tris(dimethylamino)arsine in CdTe layers grown by metalloorganic chemical vapor deposition with dimethylcadmium and diisopropyltellurium on GaAs substrates are investigated. Arsenic incorporation into $\mathrm{CdTe}$ depends on the crystallographic orientation of the layers and increases in the order $(111) \mathrm{B} \rightarrow(100) \rightarrow(310)$. Arsenic concentration in the CdTe layers is proportional to the tris(dimethylamino)arsine flow rate the power of 1.4 and an increase with decrease of the diisopropyltellurium/dimethylcadmium ratio from 1.4 to 0.5 . The as-grown CdTe: As layers had $p$-type conductivity with arsenic and hole concentrations of $1 \cdot 10^{17}-7 \cdot 10^{18}$ and $2.7 \cdot 10^{14}-4.6 \cdot 10^{15} \mathrm{~cm}^{-3}$, respectively, but with the arsenic activation efficiency not exceeding $0.3 \%$. After annealing in argon flow $\left(250-450^{\circ} \mathrm{C}\right)$ the highest hole concentration and arsenic activation efficiency were $1 \cdot 10^{17} \mathrm{~cm}^{-3}$ and $\sim 4.5 \%$, respectively. The ionization energy of arsenic determined from the temperature dependence of the hole concentration was in the range of 98-124 meV. Low-temperature photoluminescence spectra of the layers showed an emission peak with the energy of $1.51 \mathrm{eV}$, which can be attributed to donor-acceptor recombination, where the acceptor is $\mathrm{As}_{\mathrm{Te}}$ with ionization energy $\sim 90 \mathrm{meV}$. 